\title{
Study of snakebite and toxicological assessment of the biochemical concoction of snake venom
}

\author{
Sharanya Nath $^{1}$ \\ ${ }^{1}$ Affiliation not available
}

August 5, 2021

\begin{abstract}
Fear of snakes known as Ophidiophobia or Ophiophobia is a powerful and abnormal fear of snakes. A lot of psychologists, physicians and evolutionists have been fascinated by this primeval innate human emotion. Be that as it may, snakes still not are paid enough attention to adequately as agents of human sickness; also, the logical bits of knowledge given by the clinical phenotype of human envenoming have been disregarded for quite a while. Over an era of research has given that snake venom can be rich integration of pharmacologically active proteins, various protein derivatives and peptides. In this way, due to snake bite every person envenomed turns into a whiz try, giving out insight into the pathophysiological and humanitarian test. The logical investigation of snake bite can be a part of activities of venom chemicals, while exhibiting a therapeutic clinical toxicology, that sub forte of toxicology that manages the impacts of characteristic poisons and toxins of microbial, plant and animal inception on people and domesticated animals, especially their counteractive action, conclusion, treatment, the study of disease transmission, and pathophysiology.
\end{abstract}

\section{INTRODUCTION}

Snake bite is considered a typical and frequently obliterating ecological and occupational ailment, particularly in rustic regions of tropical areas in developing countries. Its general well being significance has been to a great extent overlooked by therapeutic science. Snake venoms are wealthy in toxins of proteins and peptides that have particularity for a wide scope of tissue receptors, making them clinically testing and deductively captivating, particularly for designing of various drugs.

Despite the fact that the full weight of human suffering owing to snake bites, a huge number of individuals are known to be envenomed and several thousands are sent to die or hurt by snakes each year. Preventive endeavors ought to be taken towards educating the influenced networks to utilize appropriate footwear and to lessen the danger of contact with snakes to a base through comprehension of the conduct of snakes' in general. To treat envenoming, the generation and clinical utilization of antidote must be improved. Expanded joint effort between clinicians, disease transmission experts, and research center toxicologists should improve the treatment and comprehension of envenoming.

\section{SNAKES (OPHIDIA)}

Consistently in India near around 200000 of individuals get bitten by snakes every year. Approximately out of these around 15 thousand are said to die each year. Snakes are toxic and poisonous, just as they are non-noxious and harmless. Major part of the snake population is non-harmful. Greater parts of individuals die due to dread of death instead of snake bite. In this way, it is imperative to console the individual who has 
been bitten by a snake that it is likely that the snake might be a non-harmful one. On the off chance that the snake is caught in any condition, it might be learned by examination whether it is harmful/venomous or not.

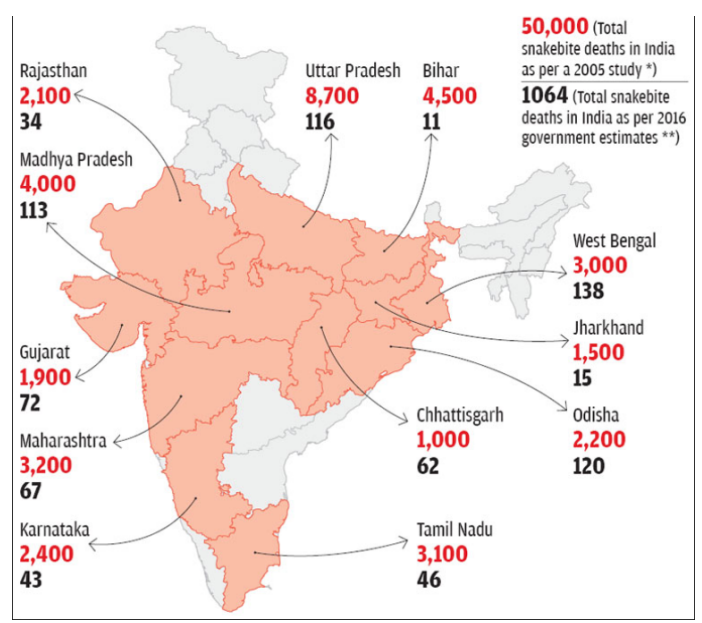

\section{Poisonous or Harmful Snakes}

The noxious snakes have a place with two families: Colubridae and Viperidae. The snakes belonging to Colubridae family are known to lay eggs. Their head is equals to or of a similar width as that their neck. The pupils are round. They are of two kinds:

1. Elapidae or land or earthbound snakes.

2. Hydrophidae or ocean snakes.

\section{Elapidiae (TERRESTRIAL SNAKES)}

The regular Elapidae snakes are cobra, king cobra, regular krait, banded krait and the vipers.

1. Cobra: It is likewise called Nag or Kala Saanp because of its dark shading. It happens all through India. It has a very much stamped hood. The hood may bear on dorsal side a twofold or single display mark. The head of this snake is not unmistakable from its neck. Its neck locale expands to frame hood. It grows its hood just when it is chafed or going to assault. In a dead snake, hood can't be acknowledged as neck and joints become firm. The normal length is $5-6$ feet.

(a) A little triangular shield normally known as cuneate or wedge shield is seen mostly between the fourth and fifth infralabial shields.

(b) Two dark spots and three dark group of bands might be seen on the focal side of hood.

(c) The caudal scales are twofold.

2. King Cobra: It is likewise called Nag Raj or Raj Samp. It is found in the Himalayas, Bengal, Assam and in slopes of South India. It is greater than regular cobra and might be $8-12$ feet in length. The hood can be less wide yet longer than normal cobra. It consists of four chevron-shaped bars on the head.

3. Regular Krait: It is discovered all over India. The regular length is $3-5$ feet. It is generally steel blue in shading and has slender single or twofold white curves over the back. These curves start somewhat a long way from the head and stretch out up to the tip of the tail. The tummy is velvety white in shading. The basic krait can be distinguished by the accompanying highlights: 
(a) The head is secured with huge shields.

(b) Four shields are available on lower lip the two sides.

(c) The scales in the focal line are huge and hexagonal till the tail.

(d) Round tail is seen.

(e) The plates under the tail resemble that present on the tummy. They are in all and not partitioned.

Hydrophidae (sea snakes)

These are seen in beach front zones. The eyes are exceptionally little, and their tails are straightened like blades. They have short, stationary teeth. The body is round. As a rule, ocean snakes are not hostile and they once in a while bite people. The venom is neurotoxic and myotoxic. Subsequently, there is extreme shortcoming because of muscle harm in bites because of ocean snakes.

\section{NON POISONOUS OR HARMLESS SNAKES}

Greater part of the snakes in India is non-toxic. The majority of the snakes have their stomach secured with transverse plates which don't expand totally crosswise over it.

\section{FATAL DOSE}

The deadly portion for regular snake venom is as per the following:

- Cobra $=12 \mathrm{mg}$

- Russell's snake/viper $=15 \mathrm{mg}$

- Krait $=6 \mathrm{mg}$

- Echis carinatus $=8 \mathrm{mg}$

\section{Common Krait (Bungarus caeruleus):}

The bite of normal krait is lethal to man. The snake is viewed as the second most noxious on the planet and first in Asia. The emission per strike fluctuates from 8 to $2 \mathrm{mg}$ of dried venom.

The venom is more poisonous than that of cobra and is viewed as multiple times (15x) more destructive than the Cobra's. $1 \mathrm{mg}$ dried toxic substance turns into the deadly portion for man. Passing may occur in five to twelve hours after the bite.

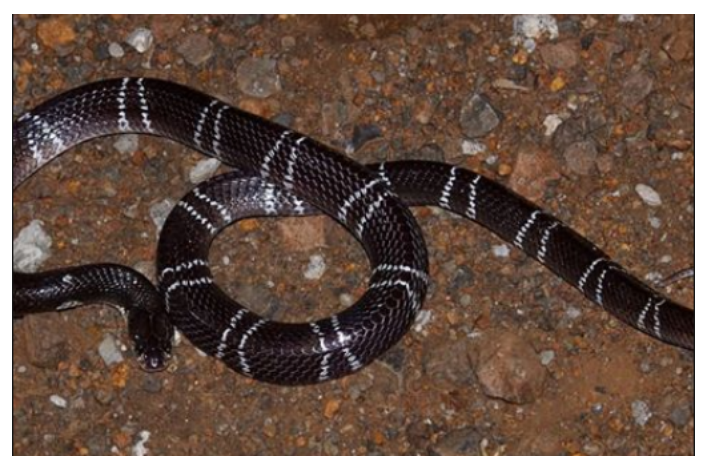

\section{Banded Krait (Bungarus fasciatus):}

Banded krait's bite is likewise deadly as different other kraits. The venom is less lethal than cobra toxin. 
Once in a while there is report of the bite by this species; it can even kill a bullock in around 20 minutes after the bite of this species.

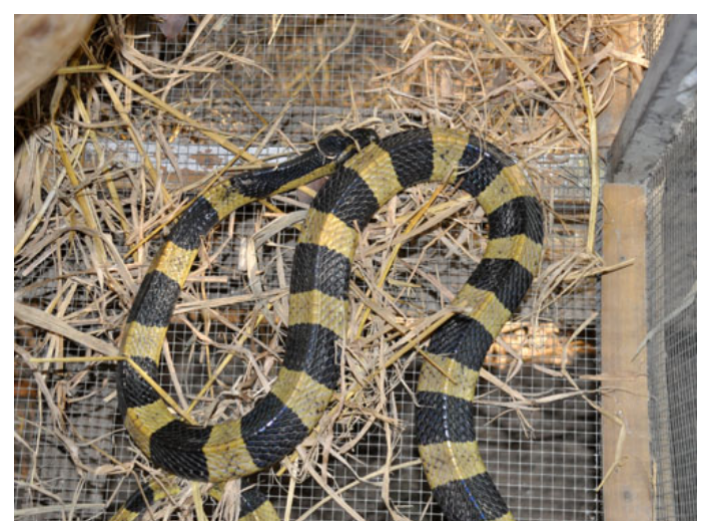

\section{Indian Cobra (naja):}

- The measure of venom discharged per strike is around $211 \mathrm{mg}$.

- $12 \mathrm{mg}$ portion of venom ends up deadly for a man. The toxic substance glands contain around $317 \mathrm{mg}$ venom.

- The cobra venom is multiple times (5x) more destructive than viper.

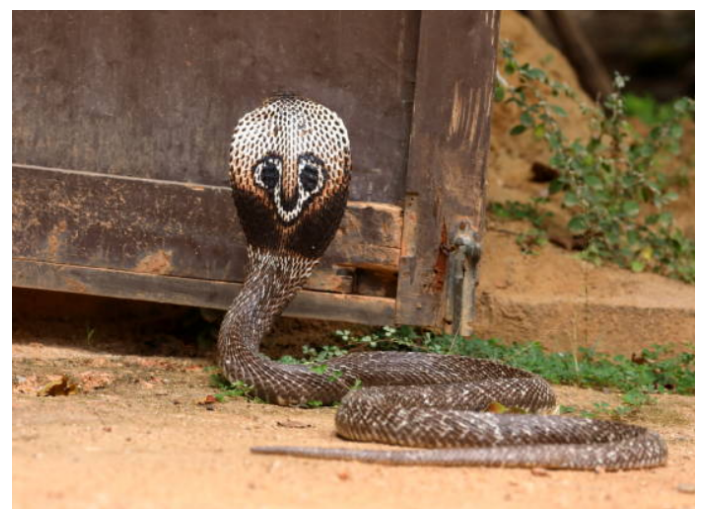

\section{King Cobra (Ophiophagus hannah):}

- The toxin is less destructive than that of cobra.

- The measure of venom that is released at a bite, proportional to ten deadly dosages to man. A person passes away in no less than 15 to 20 minutes.

- The organs yield around $650 \mathrm{mg}$ venom. A grown-up elephant dies at a solitary bite. 


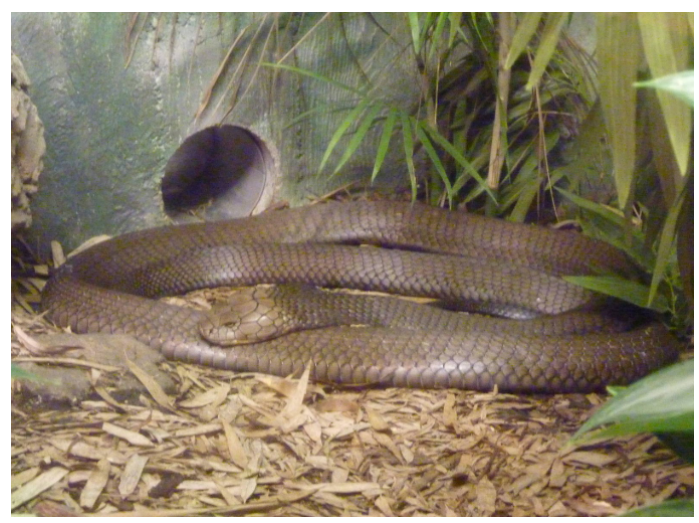

\section{Russell's Viper (Vipera russelli):}

- $72 \mathrm{mg}$ might be infused at per strike. $15 \mathrm{mg}$ portion of venom thought to be the deadly portion for man.

- The teeth are larger among Indian toxic snakes and are around $16 \mathrm{~mm}$.

- The organ contains around $108 \mathrm{mg}$ venom.

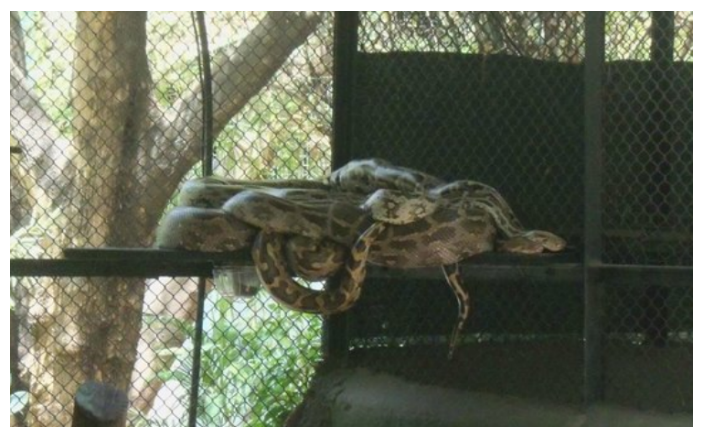

\section{Saw Scaled Viper (Echis carinatus):}

- The normal yield of dry venom by weight is around $18 \mathrm{mg}$ with a recorded greatest yield of around 72 mg.

- Around $12 \mathrm{mg}$ can be infused per strike. $8 \mathrm{mg}$ is accepted to be lethal portion for a man.

- The venom is multiple times more harmful than that of cobra and multiple times(16x) as poisonous as Russell's Viper venom. The length of the tooth is $5 \mathrm{~mm}$ as contrasted and the length of the assortment of $380 \mathrm{~mm}$. 


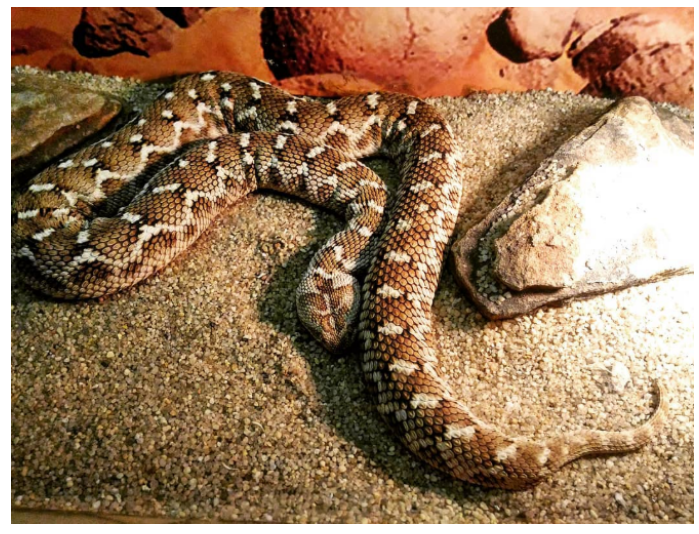

\section{THE EVOLUTION OF SNAKES AND IT'S BEHAVIOUR}

Venomous snakes are generally dispersed in pretty much every nation between the latitudes of $50^{\circ} \mathrm{N}$ and $50^{\circ} \mathrm{S}$ in the western side of the equator and $65^{\circ} \mathrm{N}$ (Scandinavia) and $50^{\circ} \mathrm{S}$ in the eastern half of the globe.

Ocean snakes are found in the Indian Ocean and Pacific Ocean between latitudes of $30^{\circ} \mathrm{N}$ and $30^{\circ} \mathrm{S}$. Ashore, venomous snakes have been found from ocean level up to heights higher than $4000 \mathrm{~m}$ in the Americas and Himalayas, and ocean snakes can dive to profundities more noteworthy than $100 \mathrm{~m}$ in the seas.

The fossils of various snakes with venomous teeth and fangs from at any rate the Lower Miocene era have been discovered. A couple of venom poisons are adjusted salivary organ emissions, though most venom qualities began from different organs through rehashed scenes of quality duplication and enlistment. Selected poisons hold the bioactivity of the tribal proteins in probably a portion of their isoforms. Cysteine crosslinked hereditary proteins are the well on the way to venture into practically differing, new poison multigene families.

Ordered and developmental relationship of many existing snake taxa have been built up, progressively through DNA-determined phylogeny. Of uncommon significance for clinicians and antidote makers has been the elucidation of the classification and ID of a few gatherings of snakes of perceived medicinal significance, for example, African spitting cobras, African- Asian saw-scaled snakes, Asian cobras (Naja spp), Russell's snakes (Daboia russelii and D siamensis), and arboreal pit snakes.

\section{THE PATHOLOGY OF ENVENOMING WITH PHYSIOLOGICAL AND BIOCHEMICAL CHARACTERISTICS}

The reptile, snake comes under cold blooded and very specific animals. A pair of salivary organs secretes a ground-breaking multipurpose enzyme liquid (venom) that stream at the season of envenoming through fine directed or notched teeth called fangs. Venom discharge in every single venomous snake seems to fluctuate in seasons; more in hotter months with high grimness and casualty. Snake is a merciless creature. Darker the snake, it secretes more venom when contrasted with a light hued. As a result of the ascent in body temperature of dull skin (poor transmitter of heat or warmth) snake, the venom is in increasingly liquid state and infused quickly with fast and most extreme amount in a brief span amid envenoming. As contradict to light hued skin in light of low body temperature, the venom is thick and henceforth less sum is infused at the season of envenoming. It is very certain that snake venom isn't a substance advanced to assault man or any huge vertebrates. Snake can bite and keep on emitting venom various occasions in progression. Most snakes infuse $10 \%$ of the accessible venom in a solitary strike with the exception of the Russell's snake which infuses $75 \%$ of put away venom in one bite because of huge long sharp fangs. Now and again snake just bite without envenoming called as "barrier bite or dry bite" while the bite with envenoming is called as the "proficient bite". Venom is a mixed liquid of at least 20 parts counting proteins, compounds, nonenzymatic polypeptide poisons, nontoxic nerve development factors, hyaluronidase, metalase, lipids, free amino acids, nucleotides, 
sugars, biogenic amines, and different activators and in activators of physiological procedures.

Snake venoms are the most intricate of every single normal venom and toxic substances. The venom of any species may contain in excess of 100 diverse poisonous and non-dangerous proteins and peptides, and furthermore non-protein poisons, sugars, lipids, amines, and other little particles. Venomous creatures and their venoms have developed to exploit numerous environmental specialties and prey species that incorporate a scope of creatures and their eggs - ie, ring worms, velvet worms, phylum mollusca, insects and arachnids, creatures of land and water, reptiles, aves, and mammals. Evolutionary weights have chosen toxins of venom that are specific for some objectives in creature tissues. The poisons of most significance in human envenoming incorporate those that affect the central neural and nervous system, cardiovascular, and haemostatic frameworks, and cause tissue rot.

The neurotoxins in snake venom can or enable block or energize neuromuscular intersections by acting at different destinations. Snake venom neurotoxins are believed to be for all intents and purposes avoided from the CNS - for example, 2 low molecular-weight phospholipases from the venom of Russell's snake were harmless when offered intravenously to rodents yet were deadly or narcotic when given intraventricularly. Be that as it may, a typical indication of snake bite is laziness, proposing the likelihood of a focal narcotic activity, for example, that related with a little non-protein poison that is found in the Ophiophagus hannah venom (King cobra).
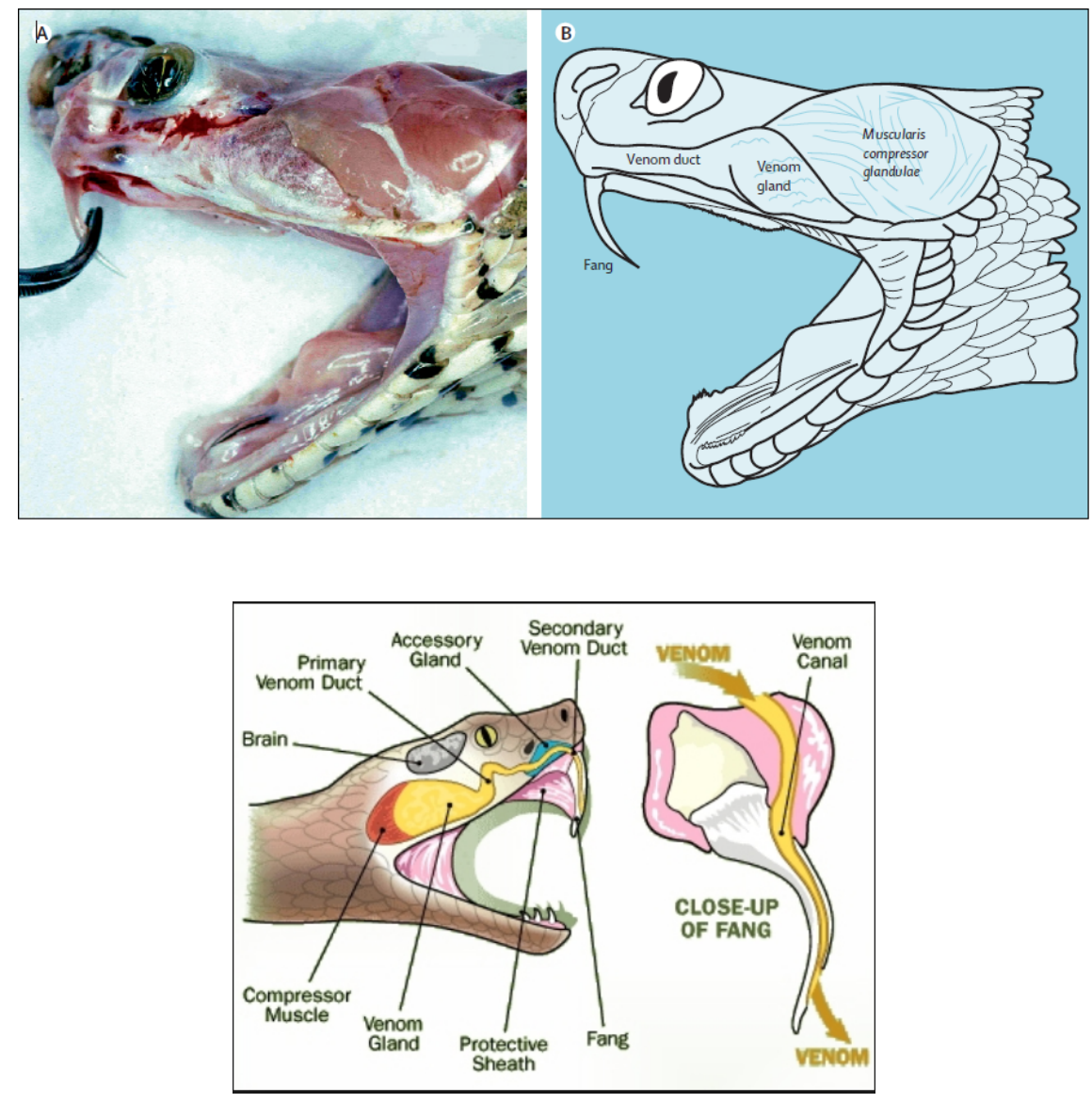

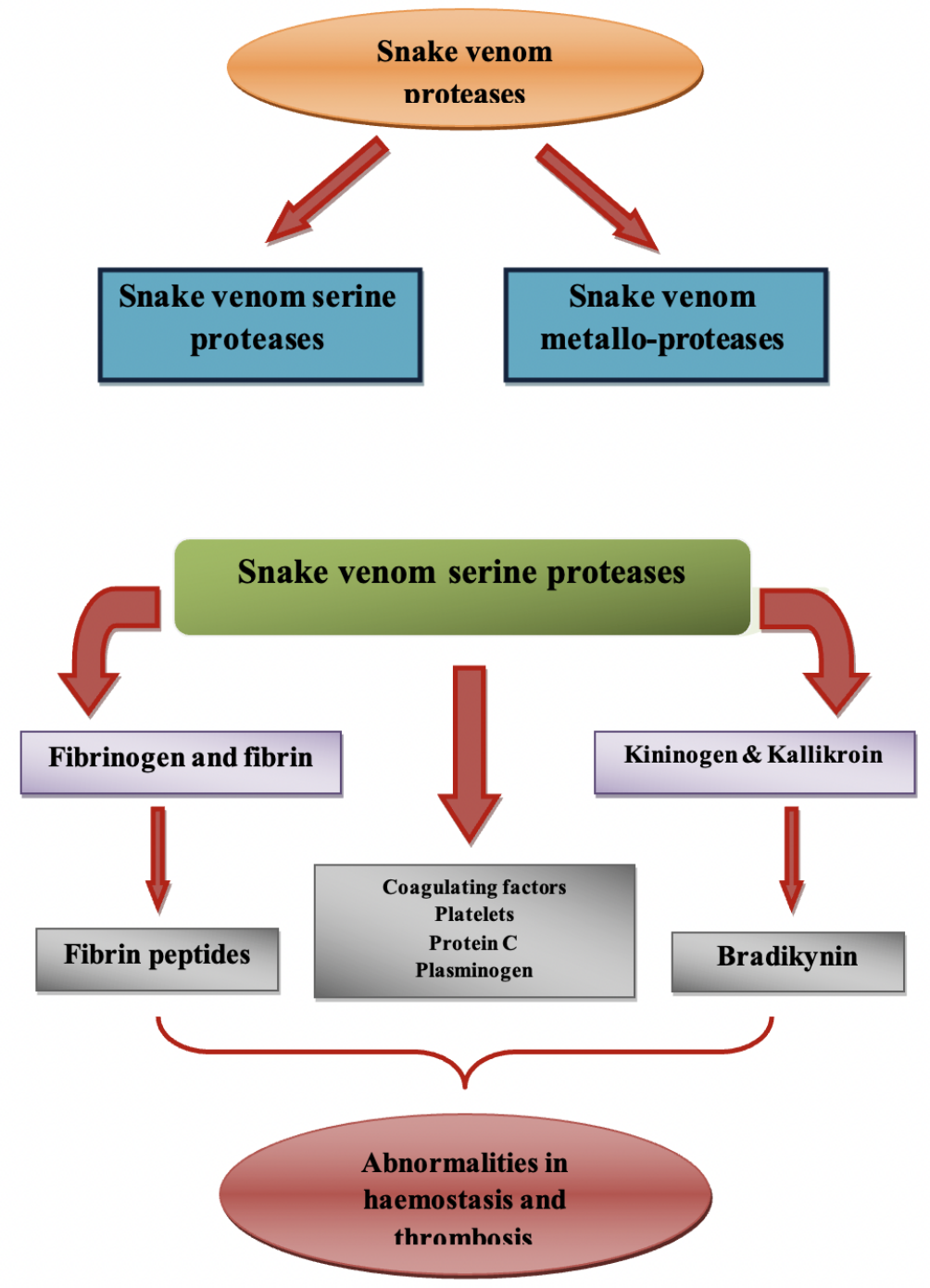

\section{BITING MECHANISM OF POISONOUS SNAKES}

The component additionally involves a similar story when arise an occurrence of Indian poisonous snakes, extraordinarily the cobra and other snake groups. The component of biting is a convoluted procedure and the arrangements of biting might be talked about in three discernible advances.

- The opening of the mouth

- The Maxilla Rotation

- The closing of the mouth

\section{I) The opening of the mouth}

Certain few seconds just before striking the digastric muscle contracts, thus the mouth opens by the muscle activity. 


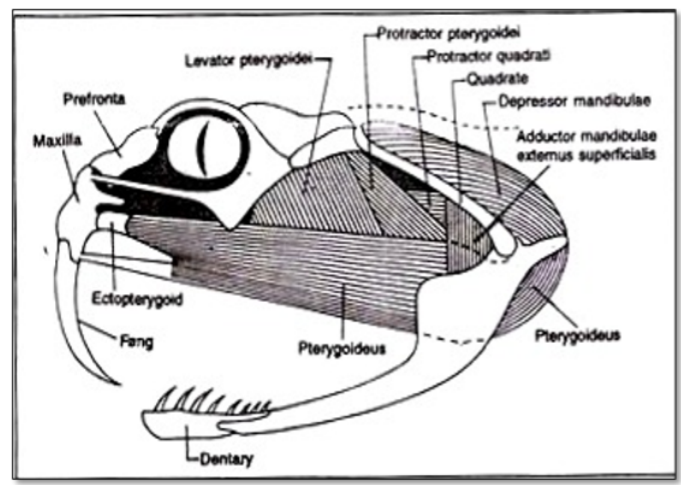

\section{II) The maxilla Rotation}

The moment the mouth opens, the lower jaw pushes ahead and a pivot of the squamosal, quadrate and mandible in connection to one another happens. Presently the sphenopterygoid muscles contract. This compression results in the forward development of pterygoid and up-pushing of the ectopterygoid.

The upward development of the ectopterygoid realizes a turn of the maxilla all alone hub round the lacrimal and as the final product the tooth is raised and goes to its striking position. The tooth is almost flat in position when the mouth stays shut. Be that as it may, amid opening of the mouth to bite, the tooth expects nearly vertical position.

The development of the pterygoid and ectopterygoid is affected by the constriction of their own muscles the protractor and levator pterygoidei which together act to push the pterygoid and ectopterygoid legitimately forward.

Therefore the maxilla pivots in its very own axis. The erection of fangs isn't identified with the opening and shutting of the mouth. The fangs can be erected freely.

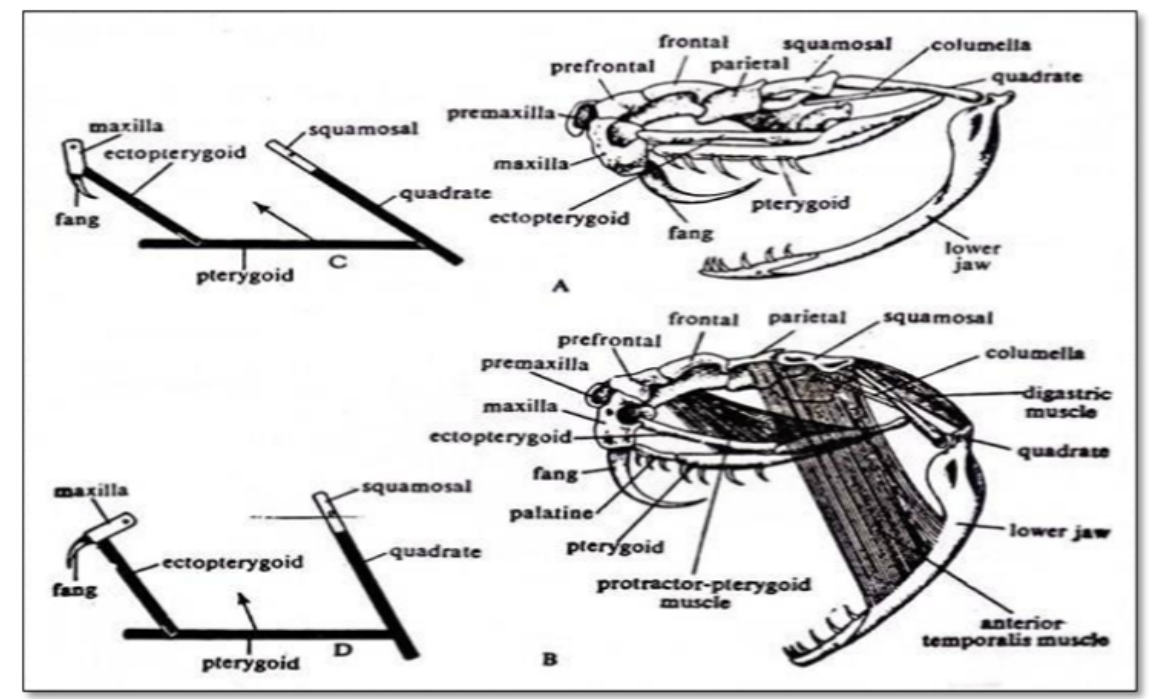

\section{III) The closing of the mouth}

This is achieved by the constriction of the temporalis muscles and sphenopterygoid muscles. The purpose of the tooth is coordinated in reverse while the mouth is shut. It requires a more drawn out investment to 
open the mouth than to close it.

\section{MECHANISM OF VENOM TOXICITY}

In spite of the fact that, as is self-evident, there is numerous mechanism of activity for only one venom, it is helpful to arrange venoms as indicated by the organization and principle methods of activity. The venoms of various kinds of venomous snakes are diverse in synthesis.

- Elapidae and Hydrophidae venoms are wealthy in neurotoxic polypeptides. These venoms are normally quick following up on nerve tissue and synapses, regularly debasing synapses or depolarizing the axonal film for extensive stretches of time, in this way keeping apprehensive motivations from being led.

- Cobra cardiotoxin acts correspondingly to depolarize heart cell films, which prompts systolic capture. Cardiotoxic venoms have a liking for cardiovascular tissue yet seem to work by comparative instruments as the neurotoxic elapid venoms.

- Crotalid neurotoxins are not layer depolarizing, but instead are opposing to acetylcholine and go about as a blocking operator at the neuro-strong intersection. Phospholipases, proteases and lytic factors contained in venom will in general reason hemolytic impacts and are to a great extent in charge of the rot that pursues viperid and crotalid bites. Cell digestion is hindered by hindrance of oxidative phosphorilation, which prompts a lacking supply of ATP for the cell. Mitochondrial electron transport is likewise hindered as Q-Cytochrome C, an electron acceptor protein in the Electron Transport Chain, is denatured.

- As snake venoms are powerful and complex, the death rate of snakebite patients is low in light of the fact that frequently there is just slight, and now and again no envenomation. Roughly $50 \%$ of treated snakebites don't hint at any envenomation whatsoever restricted impacts of venom harmfulness are hard to treat as the venom for the most part scatters into the tissue encompassing the bite quickly, be that as it may, antidotes are typically viable at treating and counteracting fundamental side effects. Normal indications of an envenomated bite are: nearby swelling (viperids and crotalids just), neighborhood torment, non-thickening of blood, and respiratory trouble (elapids and hydrophids as it were).

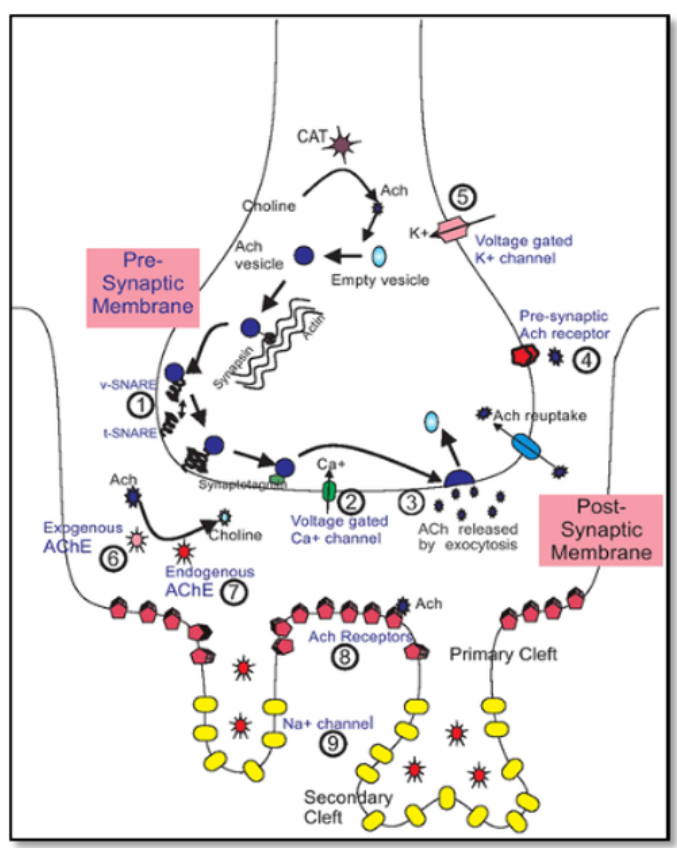




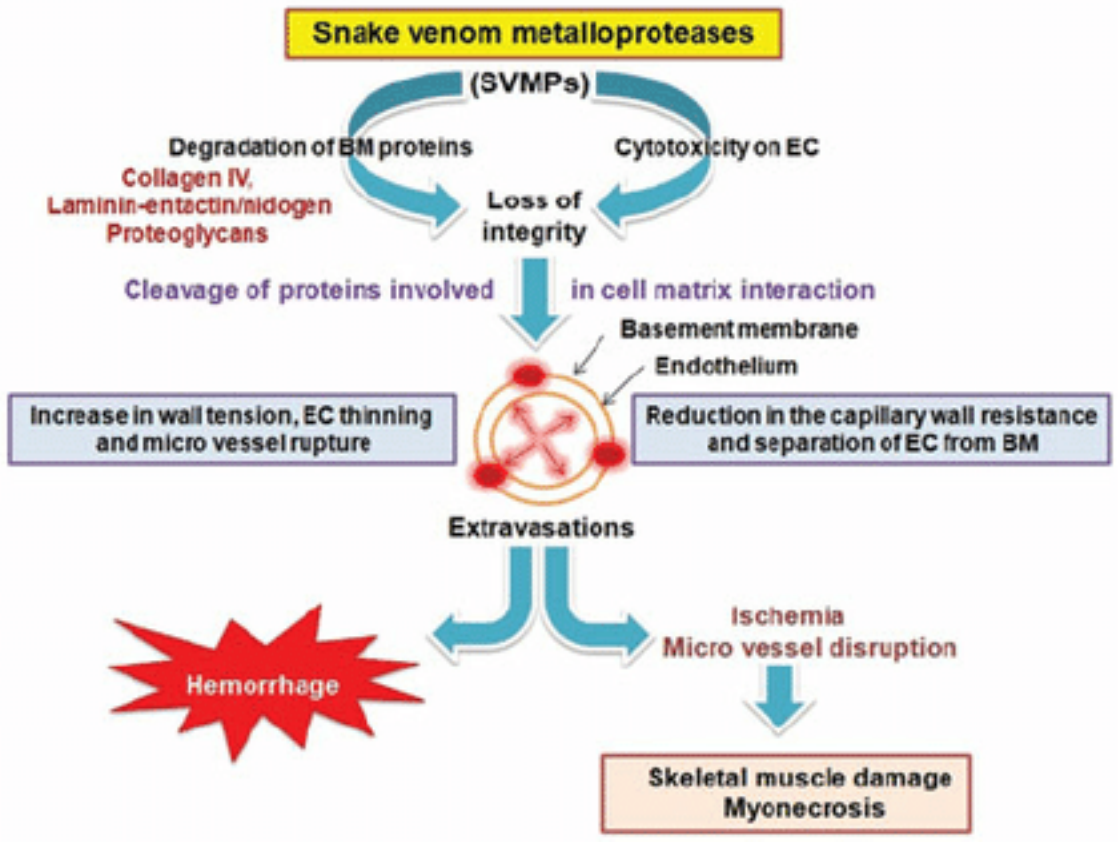

\section{EFFECTS OF SNAKE'S VENOM ON HUMANS}

The venom is for the most part brought into the subcutaneous tissue and afterward it achieves the general flow. At the point when brought straightforwardly into the vein the impact is prompt.

\begin{tabular}{|c|c|c|c|}
\hline & Name of the compounds & Occurrence & Effects \\
\hline 1. & Proteases & All snakes & $\begin{array}{l}\text { Necrosis; helps in the digestion of the } \\
\text { tissues and blood coagution. }\end{array}$ \\
\hline 2. & Hyaluronidase & All snakes & $\begin{array}{l}\text { Increases tissue permeability and thus } \\
\text { helps in the spreading of toxic sub- } \\
\text { stances. }\end{array}$ \\
\hline 3. & Phospholipase A & All snakes & $\begin{array}{l}\text { Hydrolyse lecithin to lysolecithin and } \\
\text { cause haemolysis. }\end{array}$ \\
\hline 4. & Cholinesterase & Elapids & $\begin{array}{l}\text { Block the transmission of nerve } \\
\text { impulses. }\end{array}$ \\
\hline 5. & L-amino acid oxidase & $\begin{array}{l}\text { Many colubrid } \\
\text { snakes }\end{array}$ & Cause massive tissue destruction. \\
\hline 6. & Phosphatases & All snakes & $\begin{array}{l}\text { Destroy cell membranes and cause } \\
\text { haemolysis. }\end{array}$ \\
\hline 7. & $\begin{array}{l}\text { Nucleases (Deoxyribonuclease } \\
\text { and Ribonuclease) }\end{array}$ & All snakes & $\begin{array}{l}\text { Cause hydrolysing phosphodiester } \\
\text { bonds in DNA and RNA. }\end{array}$ \\
\hline 8. & Neurotoxin & Cobra & $\begin{array}{l}\text { Exerts actions on the nervous tissues } \\
\text { and causes paralysis. }\end{array}$ \\
\hline 9. & Haemolysin & All snakes & Release haemoglobin from RBC. \\
\hline 10. & Crotamine & $\begin{array}{l}\text { Tropical rattle } \\
\text { snake }\end{array}$ & $\begin{array}{l}\text { Produces paralysis in the posterior part } \\
\text { of the body. }\end{array}$ \\
\hline 11. & Cardiotoxin & Indian cobra & $\begin{array}{l}\text { Produces a sharp fall in blood pressure } \\
\text { and causes heart stop. }\end{array}$ \\
\hline
\end{tabular}

Cobra poison:

The impacts are seen inside thirty minutes. The general shown symptoms are happiness, high heartbeat 
rate, outrageous salivation, incomplete loss of motion of tongue and larynx, heaving with vomiting and pupil contraction. The eyes stay delicate to light and awareness stays undisturbed. Breath is shallow, at last stops and passing pursues. It comes under neurotoxin.

\section{Viper poison:}

The impacts are seen inside quarter of 60 minutes. Manifestations are swelling of the injured area, discolouration occurs because of extravasation, intense copying torment, dilatation of the pupil, high heartbeat rate, bountiful vomiting and watery release from rectum.

The eyes generally lose affectability to light and cognizance is influenced. Extravasation occurs, swelling may spread and become fatal. The toxic substance of the two gatherings contrasts in properties however a viperine can harm a colubrine and the other way around. Since its haemo-toxic, the toxic substance is impact-less on individuals from same family.

\section{Krait poison:}

Venom of this snake has properties of both neuro and haemo- toxin. The kraits are exceedingly toxic and poisonous yet the non-attendance of pain, swelling, overflowing or draining raises uncertainty of bite during initial hours. Indeed, even teeth imprint don't uncover any visible spot. Side effects are fundamentally the same as with the indications of neurotoxicity of cobras.

The main indication of neurotoxicity is seen as ptosis. Different signs are extreme stomach ache, spilling of salivation, failure of respiration along with cyanosis. The reason for death is asphyxia through loss of motion of the respiratory focus.

Sea snake's poison:

The ocean snake is highly venomous. The toxic substance goes about as myotoxic which consequences for muscles, causing arrival of myoglobin that is discharged through the kidneys. The main side effects are shortcoming and soreness in the muscles.

The falling and drooping of eyes is seen and jaws become solid. Weakness bit by bit increments in such condition that the patient is unfit to lift a finger. The discharge of myoglobin gives a red stain to urine. Heart beat indicates inconsistency and demise may occur inside twelve hours after being bitten.

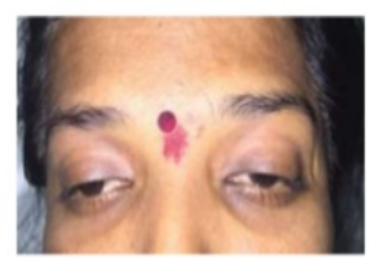

Drooping eyelids

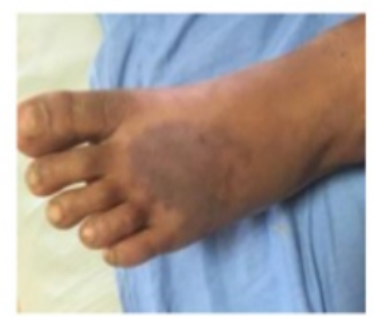

Change in color of tissue around the bite area

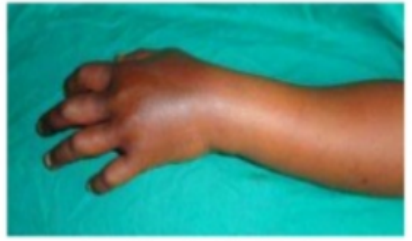

Swelling in the limb
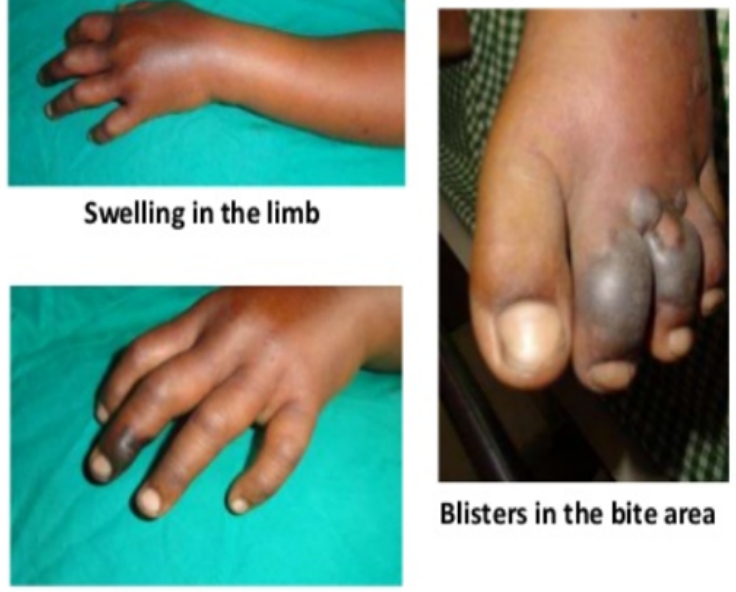

Blisters in the bite area 


\section{VENOMOUS SNAKE BITE TREATMENT:}

The emergency treatment and restorative or careful consideration are vital beyond what many would consider possible after a snake bites an individual

\section{The accompanying techniques are recommended for the people in question:}

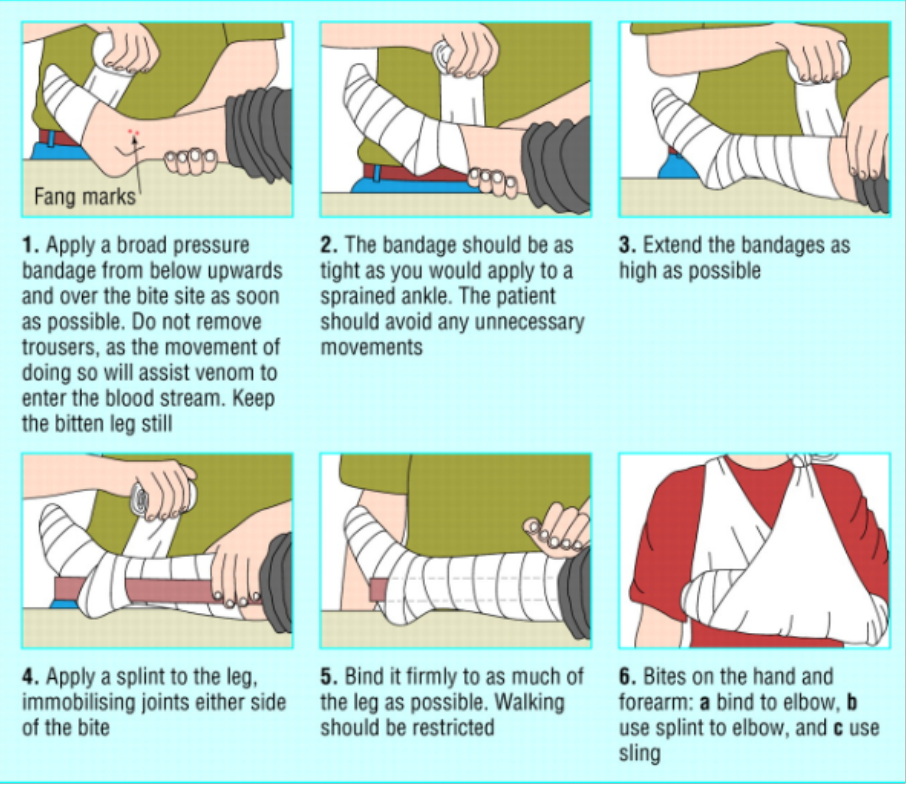

(i) Using a tourniquet or cloth ligature five to ten $\mathrm{cm}$ over the injury, toward the heart can stop the fast spreading of venom in the blood and rest of the body.

(ii) The spot should be immediately washed with clean water.

(iii) An entry point or small incission around one cm profound ought to be done or marked close about the injury with the assistance of a disinfected blade or knife.

(iv) Firstly, using force or pressure let out some blood. Secondly, suck out the envenomed blood with a suction container however it should never be done by mouth.

(v) Always try helping the exploited to keep in loosened up mind-set.

(vi) Run and seek a doctor and neutralize the poison activity by infusing antibody or antivenom (the precise measurement can be from ten to hundred $\mathrm{ml}$ ).

(vii) Handle the confusions brought about by the antibody, for example, the fever "serum sickness", a hypersensitive response to the remote proteins of the serum, serious stun conditions, for example, anaphylactic stun (brought about by arrival of histamines).

(viii) Control the injured individual warily, in light of the fact that the general taking care may accelerate the course of blood,

(ix) During the event of cobras, kraits, snake's bite the polyvalent serum ought to be injected ideally intravenously as quickly as time permits after the bite. In the event that vital, a fake treatment infusion might be recommended to console the patient. 


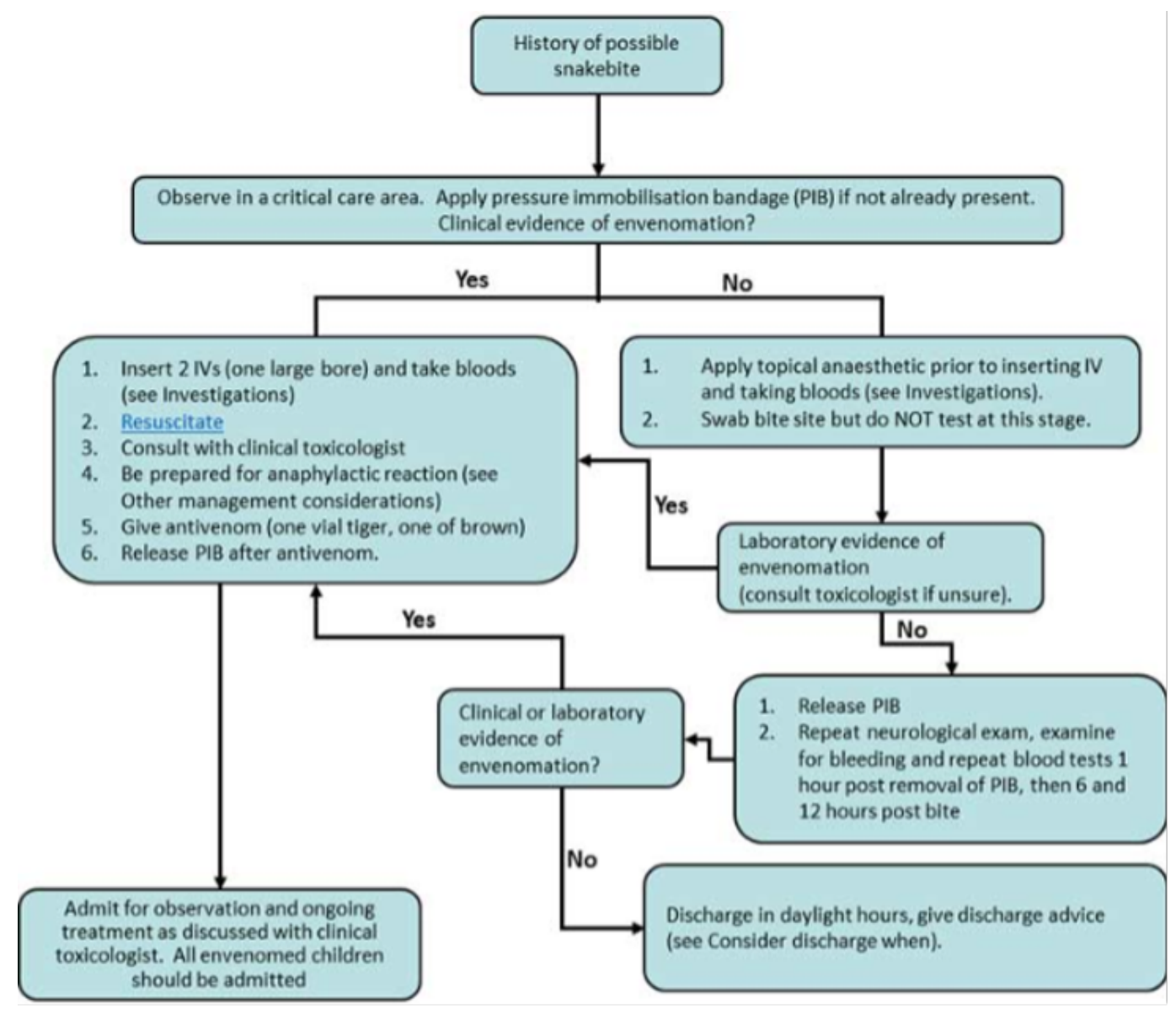

\section{References:}

1. Julien, Robert M. A Primer of Drug Action. New York. Worth Publishers. 2001

2. Lee, C. Y. (1970). Elapid neurotoxins and their mode of action. Clin. Toxicol. 3, 457.

3. Minton, Sherman A. Snake Venoms and Envenomation. New York. Marcel Decker, Inc. 1971

4. Russell, Findlay E. Snake Venom Poisoning. New York. Scholium International, Inc. 1983

5. Tu, Anthony T. Rattlesnake Venoms: Their Actions and Treatment. New York. Marcel Decker Inc. 1982

6. Tu, Anthony T. Venoms: Chemistry and Molecular Biology. New York. John Wiley \& Sons. 1977

7. Isbell LA. Snakes as agents of evolutionary change in primate brains. J Hum Evol 2006; 51: 1-35.

8. Williams D, Gutierrez JM, Harrison R, et al. The Global Snake Bite Initiative: an antidote for snake bite. Lancet 2010;375: 89-91.

9. Klauber LM. Rattlesnakes. Their habits, life histories, and influence on mankind. Berkeley: University of California Press, 1972: 2e.

10. Sclater WL. List of snakes in the Indian Museum. Calcutta: Trustees of the Indian Museum, 1891.

11. Heatwole H. Sea snakes. Malabar: Krieger, 1999: $2 \mathrm{e}$.

12. Kuch U, Muller J, Modden C, Mebs D. Snake fangs from the Lower Miocene of Germany: evolutionary stability of perfect weapons. Naturwissenschaften 2006; 93: 8487.

13. Fry BG. From genome to "venome": molecular origin and evolution of the snake venom proteome inferred from phylogenetic analysis of toxin sequences and related body proteins. Genome Res2005;15: 
403-20.

14. Fry BG, Vidal N, van der Weerd L, Kochva E, Renjifo C. Evolution and diversifi cation of the Toxicofera reptile venom system.J Proteomics 2009; 72: 12-36.

15. Mohapatra B, Warrell DA, Suraweera W, Bhatia P, Dhingra N, Jotkar RM, et al. Snakebite mortality in India: A nationally representative mortality survey. PLoS Negl Trop Dis 2011; 5:e1018. 